\title{
CAUSAL MARKERS IN JAPANESE AND ENGLISH CONVERSATIONS: A CROSS-LINGUISTIC STUDY OF INTERACTIONAL GRAMMAR
}

\author{
Cecilia E. Ford and Junko Mori
}

\section{Introduction}

The relationship between linguistic structure and the structure of social interaction has become the focus of a growing body of research (Duranti and Ochs 1979; Fox 1987; Ford 1993; Ono and Thompson to appear; Ochs, Schegloff, and Thompson in press, to name a few). ${ }^{1}$ This research has been facilitated by the careful work of conversation analysts in defining the sorts of actions accomplished in human interaction and the recurrent shapes which those actions take (for reviews see Levinson 1983; Heritage 1984; Schiffrin 1988; recent collections include Atkinson and Heritage 1984; Button and Lee 1987; Pomerantz 1993). The present study is a contribution to that research program. We consider grammar in interaction from a cross-linguistic perspective, comparing the use of causal connectors in the management of disagreement in two languages which are distinct in their basic sentence structure: English, with SVO word order and Japanese, with SOV.

Given the fundamental nature of many of the findings coming out of conversation analysis (CA), it is difficult to imagine a community of interactants that would not need to accomplish similar conversational tasks. Thus, it is likely that every linguistic community has a set of regular practices for achieving turn-transfer (Sacks et al. 1974), for indicating attention and readiness for continuation (Schegloff 1982), for initiating and completing repair (Schegloff et al 1977; Fox, Hayashi and Jasperson 1993), and for agreeing or disagreeing (Pomerantz 1984a; Levinson 1983: 332-339; Sacks 1987). What is not yet understood is to what degree there exist similar strategies for performing these functions in different languages. Are there universal needs and constraints which, by force of the work to be done in interaction, have comparable realizations in any linguistic community regardless of typological and cultural differences? CA, of the ethnomethodological variety, has been criticized as too heavily English-based, and therefore, too closely tied to culture-specific interactional patterns to be a valid source for cross-linguistic and cross-cultural generalizations (Gumperz

1 For helpful discussions of this work, we are grateful to Babara Fox, Naomi McGloin and Sandy Thompson as well as to our receptive and challenging audience at the International Pragmatics Conference in Kobe, Japan, July 25-30, 1993. We also thank the Graduate School of the University of Wisconsin-Madison for supporting this research. 
1982; Duranti 1988). Given that CA research has, in large part, concentrated on English and other European languages, this criticism is valid. However, much work clearly remains to be done in order to determine the strength of CA's claims. In the present research we are concerned with the potentially universal conversational tasks of managing agreement and disagreement (Sacks 1987; Heritage 1984; Pomerantz 1984a, 1984b). Specifically, we examine the similarities and differences in the use of Japanese and English causal connectors in sequences of talk where agreement is at issue. It has previously been demonstrated that English because has a role in such conversational environments (Ford 1993). ${ }^{2}$ It was our expectation that Japanese speakers would use similar connectors to do the same type of work, but that, as Japanese syntax offers different options and constraints, the patterns of use would likely differ in notable ways as well.

Our data consist of conversations between friends and acquaintances, an hour and a quarter in both English and Japanese (a total of two and a half hours of talk). The English participants are of ages ranging from 20 to 35 using Standard American English. The recordings took place in various casual situations: at dinner, over drinks, on a picnic, and visiting over the phone. The Japanese participants are between the ages of 26 and 34 and are graduate students at the University of Wisconsin-Madison. They are conversing in Hyoojun-go, the standard dialect. The Japanese conversations were recorded on various occasions in a T.A. office where the students regularly gather during the day. Although the Japanese speakers were in a potentially formal context, their talk is chatty and casual; the recordings were not made during official office hours or at meetings.

Both sets of conversations are transcribed according to the conventions of conversation analysis. The following are the devices that are most relevant to the concerns of our study:

$\underline{\text { Symbol }}$

(.)

hhh

thi-

$=$

[

$\underline{\text { she }}$

SHE

she:

;

$?$ $\underline{\text { Interpretation }}$

A short, untimed pause

A timed pause

Audible breath

Hyphen indicates a sound cut off

latching, a next speaker begins without a normal beat of silence between turns

Brackets indicate the onset of overlap

Prominent stress (English examples only)

Louder

Sound stretch

Ending, low falling, intonation

High rising intonation

${ }^{2} \mathrm{Kim}$ and Suh (to appear) are exploring the functions of the Korean connective nikka in conversation. 
To make our examples as accessible as possible, we have simplified the transcription notations in some examples and kept special characters and detail to a minimum.

We begin by looking at because (and 'cause) in American English conversations. We examine placement patterns (2.1) and then demonstrate the functions of because in pursuing agreement and accounting for disagreement (2.2). Following the discussion of our English conversations, we look at the Japanese causal connectors kara and datte, outlining their placement patterns (3.1) and examining their functions with respect to incipient or actual disagreement (3.2). These two connectors are used in distinct ways by Japanese conversationalists in marking connections that seem to be subsumed in English by the single conjunction because. We, then, draw explicit comparisons between causal use in English and Japanese interaction and suggest areas of similarity and divergence (4).

\section{English because}

\subsection{Placement and intonation in conversation}

A because-clause, like other adverbial clauses in English, may be placed either before or after a main clause. However, the speakers in our database of American English conversations never opt for initial placement. All of our because- and 'cause-clauses follow their main clauses. While this pattern does not violate any expectation we would have regarding what is possible in English syntax, the pattern is significantly different from those of other adverbial clauses in the corpus. In light of the large proportion of temporal and conditional clauses which are used in initial position, it is remarkable that causal clauses are never used in that position. ${ }^{3}$ Table 1 . displays the placement patterns of causal as compared with temporal and conditional clauses.

TABLE 1:

The placement of English adverbial clauses

$\begin{array}{lcl} & \text { conditional/temporal } & \text { causal } \\ \text { initial } & 47(45 \%) & - \\ \text { final } & 58(55 \%) & 74(100 \%) \\ \text { total } & 105(100 \%) & 74(100 \%)\end{array}$

${ }^{3}$ Schiffrin 1985 reports a similar finding. 
This skewed placement pattern alone raises a question as to what special functions causal connectors are performing in these conversations. ${ }^{4}$ In addition, however, of the 74 final causal connectors, just over half $(53 \%, \mathrm{n}=39)$ follow main clauses which have been completed with ending intonation (either high rising or low falling). In such cases, causal connectors introduce separate intonation units, following main clause material that has been presented as both grammatically and intonationally complete. This intonation pattern has significant interactional consequences in terms of turn taking and specific turn shapes (Ford 1993; Ford and Thompson in press). For example, in (1) below, speaker A comes to a point of grammatical and intonational completion at the end of the first line. At the arrow, he adds an intonationally separate causal clause onto the previous turn unit.

(1) (YG99)

A: .hhh Well do you think it's umm (0.2) ahm (0.2) stress?

(.)

--> 'cause a lot of back-I know back pain, (0.2) comes with stress.

In contrast, conditional and temporal connectors introduce final and intonationally separate units only $22 \%$ of the time in the same corpus.

TABLE 2:

Intonational features of final adverbial clauses

$\begin{array}{lcl} & \text { conditional/temporal } & \text { causal } \\ \text { bound } & 45(78 \%) & 35(47 \%) \\ \text { separated } & 13(22 \%) & 39(53 \%) \\ \text { Total } & 58(100 \%) & 74(100 \%)\end{array}$

In terms of placement and intonational connectedness, then, we find two striking patterns with regard to causal connectors. First, unlike other adverbial connectors in the data, they are used exclusively in final position. And second, as introducers of elaboration for main clauses, they commonly appear after the main clause has been presented as not just grammatically but also intonationally complete. That is, English because and 'cause regularly begin separate intonation units. Interestingly, in terms of traditional rules for written English, such separate adverbial clauses are not acceptable; if punctuated as new units, following a period (full stop) at the end of the main clause, these causal elaborations would be considered "fragments" (Danielewicz and Chafe

4 Ford (1993) examines the functions of temporal, conditional, and causal conjunctions in American English conversations. 
1985; Ford 1992).

The functions of initial and final adverbial clauses under continuous intonation contours have been examined in English in terms of foregrounding and backgrounding (Ramsay 1987), topic continuity (Schiffrin 1985), and their roles in the thematic progression of texts (Linde and Labov 1975; Chafe 1984; Ford and Thompson 1986). However, the functions of separated, final adverbial clauses is less well-understood. This is probably because studies of adverbial clause placement in spoken discourse have tended to concentrate on the flow of information rather than the interaction between speakers. Ford $(1992,1993)$ has, to our knowledge, been the first to suggest that final adverbial clauses presented after ending intonation commonly result from interaction between speaker and addressee rather than as afterthoughts, a label implying that such clauses are products of a single individual's cognitive processes.

In the next section, we will examine the particular interactional functions for which speakers in these conversations are using intonationally separate causal elaborations.

\subsection{Because in environments of actual or incipient disagreement}

As background for a discussion of the interactional emergence of because, a brief review of some basic principles of conversational structure is in order. A pervasive feature of the sequential development of conversation is the manner in which each individual turn is oriented to or directly responsive to a previous turn (Schegloff 1972; Sacks and Schegloff 1973; Pomerantz 1978, 1984a\&b; Sacks 1987). In fact, a strong tendency has been observed for interlocutors to work toward affiliation, alignment, or agreement with one another and to systematically avoid disagreement, which is treated as trouble and requires explicit accounts and excuses. A term used by CA researchers to encompass this pattern is preference organization. The word preference here is meant to denote a normative pattern rather than a psychological stance, though it is difficult to understand the pattern without sensing the operation of some attitudinal bias. Put as simply as possible, research on preference structure has found that particular turn types such as questions, requests, invitations, assessments, complaints, to name a few, make certain next turns expectable. More precisely, they make a certain range of next turns relevant (adjacency pairs, Schegloff and Sacks 1973; Levinson 1983: 303-308). So, for example, a request for information may be followed by an answer containing that information or by some declination plus an account for that declination.

Preference organization predicts that there are typically preferred and typically dispreferred responses to given turn types. Preferred responses are delivered with a minimum of delay, without particular hesitations ( $u \mathrm{~h}, \mathrm{uhm}$ ) or reluctance tokens (well), and preferred responses are typically direct and unmitigated. On the other hand, dispreferred responses are treated as "to be avoided". This quality is exhibited in several recurrent characteristics of dispreferreds: They are often preceded by pauses. They are initiated with hesitations and displays of reluctance. Their message of disaffiliation with a stance taken by the previous speaker is typically clothed in mitigation, indirectness, 
and sometimes, displays of partial agreement (Pomerantz 1984a; Sacks 1987). Dispreferred turns are also regularly followed by accounts or excuses (Levinson 1983: 332-338; Heritage 1984: 269-273; Firth to appear). Heritage, using the case of invitations, offers the following contrasting examples:

(2) Preferred: Simple acceptance, no delay (in fact, overlapping response) (SBL:10:12)

B: Why don't you come and see me some [times

A: [I would like to

(3) Dispreferred: Delay, preface, show of appreciation, indirect refusal, and account (SBL:10:14)

B: Uh if you'd care to come over and visit a little while this morning I'll give you a cup of coffee.

A: hehh Well that's awfully nice of you, I don't think I can make it this morning .hh uhm I'm running an ad in the paper and-and uh I have to stay near the phone.

What we see, then, is that the characteristic shapes of responses reflect their status as preferred or dispreferred. Preferred responses feature little or no delay, direct statements, and no accounting, and dispreferreds display delays, hesitations, mitigations, and accounts.

The characteristic account portion of dispreferred responses is one of the locations, in our data, in which because is used to introduce an independent intonation unit. In sequences such as that in (4) below, the 'cause at the arrow emerges specifically in the context of a dispreferred response.

(4) (AR97) Because introducing the account component of a dispreferred response

A: Did you get your (.) your first pay check from it?

(.)

A: $\quad[$ at least?

-- R: [NO: I won't get that for a couple of weeks yet.=

A: Oh.

A: $\quad[$ Well

(.)

$->$ R: ['cause it takes a long time.

A: At least it's in the bank

$(0.5)$ 
R: $\quad$ Yeah it will be.

$(0.4)$

R: $\quad$ It will be.

At the first arrow, $\mathrm{R}$ disagrees with the positive polarity of A's original question. At the second arrow, $\mathrm{R}$ provides the account for that disagreement. The because elaboration emerges from the orientation of both $\mathrm{R}$ and $\mathrm{A}$ toward the expected agreeing response.

The next example also contains a causal conjunction introducing the account for a dispreferred. Notice that A's response also shows hesitation, prefacing, and indirectness.

(5) (TG682) Because introducing the account component of a dispreferred. A is inviting $B$ to go to the city the next day.

A: Maybe if you come down, I'll take the car.

B: $\quad t-$ We:ll, uh - you know I-I don't want to make anything

--> definite. Because I-you know I jus::- I jus::t thinki:ng today all day riding on the trai:ns, hhuh-uh

Thus, we find that causal clauses emerge interactionally as introducers of accounts and excuses for dispreferred responses.

Because also emerges interactionally in relation to another aspect of preference structure. This aspect involves one of the motivations for the observed delays, hesitations, and prefaces which precede the delivery of the actual disagreeing component of a dispreferred response. When one delivers an affiliative response in an immediate and unmitigated way, form and message coincide: not only does the respondent claim agreement, but that agreement is embodied in the directness and immediacy of the turn in which it is delivered. Overlapping responses such as that in example (2) are particularly nice illustrations of this iconicity. Conversely, the hesitations and prefaces associated with disagreement are in themselves displays of the reluctance of a speaker to deliver a dispreferred response. Importantly, for our discussion of because, the pauses, hesitations, and prefaces that come before the actual disagreement component also allow the previous speaker an opportunity to add on to her/his turn in order to save both speakers from the "face" problems inherent in disagreement (Goffman 1955; Brown and Levinson 1978).

In the following example, note that the pause after A's first offer could foreshadow upcoming disagreement from B. In the light of this interpretation, A adds another increment to the turn, an increment that could encourage agreement from B. 
(6) (Davidson 1984)

A: oh I was gonna sa:y if you wanted to:, you could meet me at UCB and I could show you some of the other things on the compu:ter,

(.)

$-->$

Maybe even teach you how to program Ba:sic or something. $(0.6)$

B: Well I don't know if I'd want to get all that invo:lved,

In the next example, we see that an addition in the face of possible disagreement can be successful in creating a context for agreement.

(7) (Levinson 1983: 335)

R: What about coming here on the way

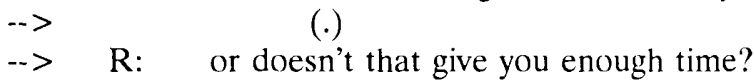

C: Well no I'm supervising here.

After the pause (first arrow), $\mathrm{R}$ revises the polarity of what would constitute an agreeing response. At the second arrow, $\mathrm{R}$ 's turn anticipates a negative response. The fact that declination is now made expectable and affiliative removes some of the force from this potentially face threatening interchange. Thus, the delay and prefacing characteristic of dispreferred turns work very nicely to help interlocutors jointly avoid outright disagreement.

Now let us look at the work of because in the extension of turns in pursuit of agreement. First, we will look at a longer version of example (1):

(1) (YG99) Because prompted by pause

A: $\quad$.hhh Well do you think it's umm (0.2) ahm (0.2) stress?

(.)

--> 'cause a lot of back- I know back pain, (0.2) comes with stress.

R: .hhh We:ll I'm thinking it might be uhh (0.2) I um: (0.5) I haven't ever

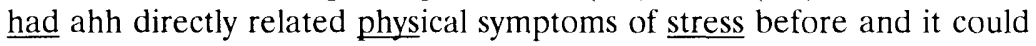
easily be that

A:

(0.2) [ but that-

[ Yeah but look what's happening though.

As in examples (6) and (7), the fragment in (1) contains a turn that is extended after a pause, a pause that could well be an indicator of incipient disagreement. A's 
extension at the arrow is introduced by because. It adds support to the previous turn increment, thus possibly improving the chances of its receiving an agreeing response. Note that R's response does indeed display features of disagreement: hesitation, preface, mitigated agreement "yes but.." format (see Pomerantz 1984 for more on the role of partial agreement plus but in disagreeing sequences).

Example (8) shows turn extensions prompted by a pause and a repair initiator (Levinson 1983: 339-342; Schegloff, Jefferson, and Sacks 1977). In this fragment, A is describing his new job at a television studio:

(8) (AR263) Because prompted by pause and repair initiator (at third arrow)

A: .hh but the thing is, the- they might get thei:r $(0.2)$ the project ca:ncelled.

$->\quad(0.2)$

$->$ A: becau:se [(they

$->$ R: $\quad[$ What this (.) wa:r project $=$

-- A: Yeah because ABC got bought ou:t?

$(0.2)$

A: $\quad$ Did you hear about tha:t? =

R: = Yeah,

A: And that they're real tight wa:ds?

We see again in (8) that causal extension is prompted by interactional trouble and delivered in pursuit of alignment between speaker and recipient. The first indication of potential trouble is the pause (at the first arrow), after which A begins a causal extension. R's repair initiation (at the third arrow, overlapping with A's first attempt at a because elaboration) targets the specific problem he is having with A's original turn: $\mathrm{R}$ was not clear on the referent of the project, which, given the definite article, is presented as shared information. Note the rising intonation on each of A's turns beginning at the fourth arrow. This is referred to as try marking in CA, and is found where shared reference is at issue. Thus A's causal elaboration initiates a series of understanding checks aimed at establishing mutual understanding in order for the A's larger agenda, reporting on his job situation, to continue.

What we have seen in this section is that the use of because and 'cause as separate intonation units is associated with speaker-addressee interaction. $85 \%(n=33)$ of the cases of causal elaborations presented under independent intonation contours in the present corpus are best understood as emerging from negotiation between speakers and recipients and primarily aimed at achieving affiliation or shared understanding, as well as at accounting for disagreement when it is not avoided. ${ }^{5}$

${ }^{5}$ Of the total of 33 interactionally emergent causal extensions, 9 are accounts, 18 are pursuits, and 6 are collaboratively achieved. In the latter cases, the production of the clause complex is shared by two speakers, the causal extension being added by a next speaker. Such co-constructed 
Given the regular emergence of English causal extensions in the environments of actual or potential disagreement, we posed the question whether causal connectors might function in a similar manner in a language whose syntax favors initial placement of adverbial clauses. Do Japanese conversationalists use causal extensions to account for dispreferreds and pursue agreement? What structural configurations do such extensions take given the expected differences in "branching" direction for dependent clauses? In the next two sections, we explore the placement and functions of causal connectors in Japanese conversations.

\section{Japanese causal connectors}

\subsection{Canonical order and postposing in conversation}

Typologically Japanese is a head-final language while English is head initial. Accordingly, the structure of a sentence which contains the causal connective particle kara differs from one with because in English.

$(9)^{6}$

$\begin{array}{lllllll}\text { Peepaa } & \text { kaite } & \text { nai } & \text { kara watashi } & \text { wa dame nan } & \text { desu yo. } \\ \text { paper } & \text { write } & \text { Neg } & \text { because I } & \text { Top not-good } & \text { Cop FP } \\ \text { "Because I haven't written any paper, I have little chance." } & \end{array}$

The connective particle comes at the end of the clause and marks the preceding part as a causal clause. Further, in the canonical order, the main clause is expected to follow the causal clause. Thus, unlike English, final causal clauses are not used in Japanese expository writing.

What is interesting is that, despite this typological difference, we observe a similar tendency in the placement of causal clauses in English and Japanese

extensions are by definition interactionally achieved; however we do not discuss these cases further in the present article (see Ford 1993; Lerner 1987, 1991; Ono and Thompson forthcoming). The following is an example of collaboratively produced causal extensions. At the arrow, H adds a causal extension to D's previous turn:

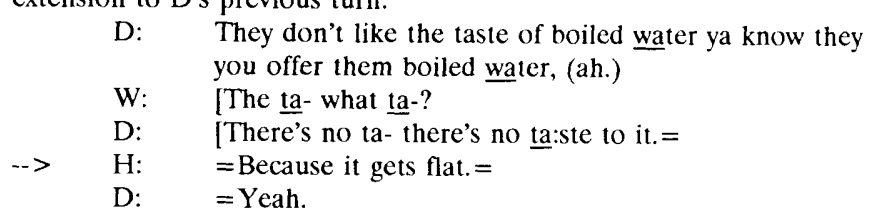

${ }^{6}$ See appendix for key to Japanese morpheme-by-morpheme abbreviations. 
conversations. That is, a final kara-clause, which is considered non-canonical in traditional grammar, is also used frequently in Japanese conversation. Table 3 shows the placement pattern of causal as opposed to conditional and temporal clauses in Japanese.

TABLE 3:

The placement of Japanese adverbial clauses

initial conditional/temporal ${ }^{7}$

causal

final

$178(91 \%)$

total

$17(9 \%)$

$61(53 \%)$

$195(100 \%)$

$54(47 \%)$

$132(100 \%)$

Although not all the causal clauses are placed finally in Japanese, final placement of the causal clauses, i.e., kara-clauses, constitutes almost half of the cases $(47 \%, n=54)$. This is significantly more frequent than the final placement of conditional/temporal clauses $(9 \%, n=17)$. Further, as seen in Table 4 , a greater number of final causal clauses $(93 \%, \mathrm{n}=50)$ are intonationally separated from their main clauses, as compared to the final conditional/temporal clauses $(42 \%, n=7)$.

TABLE 4:

Intonational features of final adverbial clauses

bound conditional/temporal

causal

$10(59 \%)$

separated

$7(42 \%)$

$4(7 \%)$

total

$17(100 \%)$

$50(93 \%)$

$54(100 \%)$

These facts, along with our findings for the English counterpart, because, lead us to the following questions; in what environments are these final kara-clauses used? What interactional functions do these clauses perform?

The frequent use of non-canonical order in spoken Japanese, has been the subject of several recent studies (Ono and Suzuki 1992; Fujii 1992; Simon 1989, among others). Fujii, for instance, claims that main clauses are asserted first to accomplish pragmatically marked functions in discourse, and that postposed adverbial clauses have an informational function with respect to main clauses, i.e. the speaker adds, confirms, or emphasizes background information. While her study deals with the pragmatic

\footnotetext{
7 The conditional/temporal clauses here include ba, $\underline{\text { tara, }} \underline{\text { to }}, \underline{\text { toki. }}$
} 
motivation of the speaker's use of the non-canonical order, it is based on a quantitative analysis ${ }^{8}$ and does not elaborate why the speaker needs to have the postposed adverbial clause to add, confirm, or emphasize background information in particular environments.

In the next section, we will examine the interactional functions of these intonationally separated, final kara-clauses. Before moving on to that section, however, it is necessary to introduce another connector which is comparable to because, the connective datte. Datte is different from the connective particle kara in terms of its location in a clause. That is, while kara is placed at the end of the clause and marks the preceding clause as causal, datte is usually in sentence-initial position and marks the following part as its domain?.

The following examples illustrate the differences between kara and datte with respect to placement and domain:

$\begin{array}{lllllll}\text { Tore masu } & \text { yo } & \text { demo. Linguistics } & \text { dat } & \text { tara } & \text { juuhachi } & \text { taNi } \\ \text { can-take } & \text { FP } & \text { but } & \text { Cop } & \text { if } & \text { eighteen } & \text { credit }\end{array}$

da kara.

Cop because

"You can, though. Because Linguistics only requires eighteen credits."

(11)

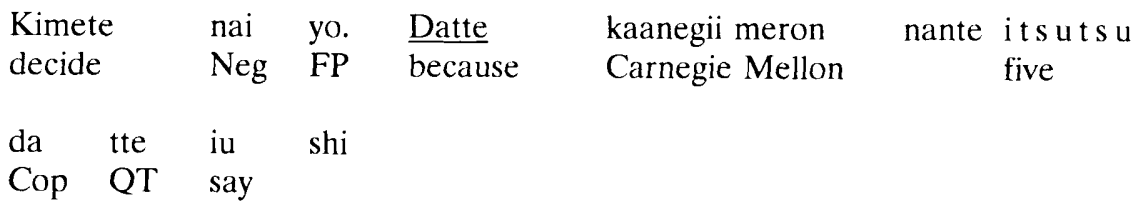

"I haven't decided. Because Carnegie Mellon for instance requires five (references)."

The meaning of datte has been controversial as it can be translated either as but or because depending on the context.

\footnotetext{
${ }^{8}$ She measures scope, foreground versus background, comprehensibility, and pragmatic markedness of each clause.

${ }^{9}$ Datte can also appear sentence-internal position like the English however or therefore.
} 


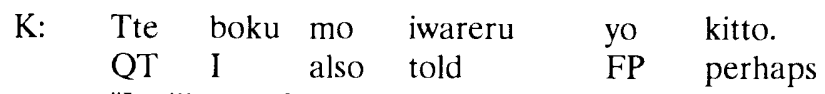

"I will be refused, too, perhaps."

$\mathrm{N}: \quad \frac{\text { Datte ima totteru jan. }}{\text { but now taking }}$

"But you are taking (his class) now, right?"

Nevertheless, what is common between the cases where datte is translated as because and but is that in both cases datte is used "to introduce an utterance in which the speaker justifies his or her behavior or opinion (Matsumoto 1988)." Maynard (1992: 83 ) also suggests that "datte prefaces support for position in conversation when one is challenged or when one challenges." These functional definitions of datte suggest that this term is responsive to an immediate problem in interaction as is the English conjunction because.

Then, how are these two alternatives used differently in Japanese interaction? The interactional functions of kara and datte will be addressed in the next section.

\subsection{Japanese causal connectors on a continuum of disagreement}

In section 2.2, we discussed the use of English causal elaborations in negotiating agreement and shared understanding. Final because clauses are used to shape dispreferred responses by providing accounts or excuses, or to pursue a recipient response by introducing more background information for understanding. In our database, we also find that Japanese speakers use final kara-clauses presented under separate intonation contours as well as the sequences introduced by datte to manage interactional problems. A difference is that the Japanese conversationalists use two different connectors, the choice of which seems not random but determined by the interactional environment. Maynard $(1992,1993)$ has also observed the use of datte in introducing dispreferred responses, but our interpretation diverges significantly from hers (section 4).

First let us look at the cases where the speaker is handling a dispreferred response.

(13) T: Amerika josei $\quad$ wa ja ikaga doo desu ka?
America women Top then how how Cop Q
"What do you think of American women then?"

$\begin{array}{llllll}\text { S: } \quad(0.8) & \begin{array}{l}\text { Nakanaka } \\ \text { not-easily }\end{array} & \begin{array}{l}\text { hitokoto } \\ \text { one-word }\end{array} & \text { de } & \text { iemasen } & \text { nee. } \\ \text { can't-say } & \text { FP }\end{array}$ 


$\begin{aligned} & \text { Ano: boku no: un honto iroNna } \\ & \text { well I Gen yeah really various-kind people }\end{aligned}$ exist
$\begin{aligned} & \text { kara:. } \\ & \text { because }\end{aligned}$
"(0.8) I can't say so easily. Well, my, yeah because really there are
various kinds of people."

A preferred response in this case would be a straightforward answer to the question. Therefore, speaker S, who cannot provide such an answer immediately, faces the problem of how to appropriately deliver a dispreferred response. He delays his reply, shows his reluctance, and shapes the response towards agreement by providing an account marked with the conjunction kara (at the arrow). As we mentioned earlier, accounts are typical features of dispreferreds. Kara, like because, is associated with the account portion of dispreferred responses.

The connective datte is also used in disagreement situations to introduce accounts. However, there is a difference in the shape of dispreferred turns with datte as opposed to kara. Compare the next example to (13).

\begin{tabular}{|c|c|c|c|c|c|c|c|c|}
\hline (14) & $\mathrm{N}:$ & $\begin{array}{l}\text {... Kimeta } \\
\text { decided } \\
\text { "Have you }\end{array}$ & $\begin{array}{l}\text { no? } \\
\text { Q } \\
\text { ecided }\end{array}$ & $\begin{array}{l}\text { Iku } \\
\text { sev } \\
\text { eve }\end{array}$ & $\begin{array}{l}\text { ka } \\
\text { plac }\end{array}$ & $\begin{array}{l}\text { apurai-suru } \\
\text { apply } \\
\text { to apply?" }\end{array}$ & $\begin{array}{l}\text { tokoro } \\
\text { place }\end{array}$ & $\begin{array}{l}\text { wa. } \\
\text { Top }\end{array}$ \\
\hline$-->$ & $\mathrm{K}:$ & $\begin{array}{l}\text { Kimete } \\
\text { decide }\end{array}$ & $\begin{array}{l}\text { nai } \\
\text { Neg }\end{array}$ & $\begin{array}{l}\text { yo. } \\
\text { FP }\end{array}$ & $\begin{array}{l}\mathrm{Da} \\
\text { bec }\end{array}$ & $\begin{array}{l}\text { kaanegii } \\
\text { se Carnegie }\end{array}$ & $\begin{array}{l}\text { meron } \\
\text { Mellon }\end{array}$ & $\begin{array}{l}n \text { a } n t e \\
\text { five }\end{array}$ \\
\hline & & $\begin{array}{l}\text { itsutsu } \\
\text { five }\end{array}$ & $\begin{array}{l}\text { da } \\
\text { Cop }\end{array}$ & $\begin{array}{l}\text { tte } \\
\text { QT }\end{array}$ & $\begin{array}{l}\text { iu } \\
\text { say }\end{array}$ & shi. & & \\
\hline
\end{tabular}

"I haven't. Because Carnegie Mellon, for instance says five."

$\mathrm{N}: \quad \mathrm{E}$ ?

what

"What?"

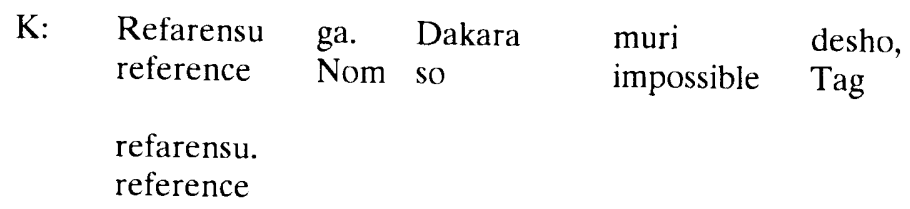


"References. So it's impossible to get those references, right?"

In (14), K's dispreferred response does not have any preface and follows immediately after N's question. That is, unlike the typical shape of dispreferred turns, there is no delay or mitigation of the disaffiliative force. Japanese speakers seem to choose between the two alternatives for causal elaboration depending on the degree of disagreement they are expressing. The following example which has both datte and kara in a continuous sequences may clarify how these two connectors are used in negotiation toward agreement.

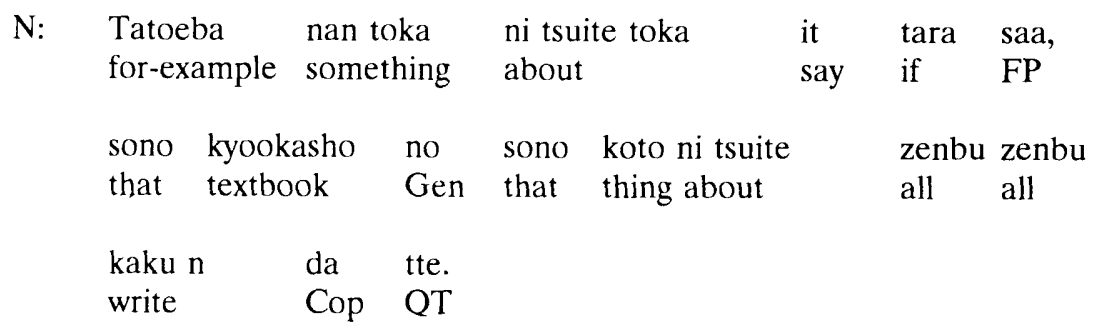

"For example, if there is a question about something, she says she writes everything, everything about the issue in the textbook."

K: $\quad$ Hee.

huun

"Huun."

$\begin{array}{llllll}\text { N: } & \text { Ii ten toru } & \text { wa } & \text { na } & \text { korya. } \mathrm{h} \mathrm{h} \mathrm{h} \mathrm{h} \mathrm{h} & \text { Maa= } \\ & \text { good grade receive } & \text { FP } & \text { FP this-Top } & \text { well }\end{array}$ "No wonder she can get good grades, in this way. Well"

\begin{tabular}{|c|c|c|c|c|c|c|c|c|c|c|}
\hline --> K: & $\begin{array}{l}=\text { Demo } \\
\text { but }\end{array}$ & & & $\begin{array}{l}\text { da } \\
\text { Cop }\end{array}$ & $\begin{array}{l}\text { ne. } \\
\text { FP }\end{array}$ & & $\begin{array}{l}\text { Boku } \\
\text { I }\end{array}$ & $\begin{array}{l}\text { dat } \\
\text { Cop }\end{array}$ & $\begin{array}{l}\operatorname{tar} c \\
\text { if }\end{array}$ & $\begin{array}{l}\text { sooiu } \\
\text { such }\end{array}$ \\
\hline & $\begin{array}{l}\text { ko } \\
\text { child }\end{array}$ & $\begin{array}{l}\mathrm{ni} \\
\text { to }\end{array}$ & $\begin{array}{l}\text { wa } \\
\text { Top }\end{array}$ & $\begin{array}{l}\text { waru } \\
\text { bad }\end{array}$ & $\begin{array}{l}\text { ter } \\
\text { gr: }\end{array}$ & & $\begin{array}{l}\text { ageru } \\
\text { give }\end{array}$ & $\begin{array}{l}\text { ne. } \\
\text { FP }\end{array}$ & & \\
\hline
\end{tabular}

"But I disagree. As for me, I would give a bad grade to such a child." 
N: $\quad$ Hee

huun

"Huun."

\begin{tabular}{|c|c|c|c|c|c|c|c|}
\hline \multirow[t]{2}{*}{$--->$} & \multirow[t]{2}{*}{$\mathrm{K}:$} & $\frac{\text { Datte }}{\text { because }}$ & $\begin{array}{l}\text { jibun } \\
\text { self }\end{array}$ & $\begin{array}{l}\text { no } \\
\text { Gen }\end{array}$ & $\begin{array}{l}\text { iken } \\
\text { opinion }\end{array}$ & $\begin{array}{l}\text { zenzen } \\
\text { at-all }\end{array}$ & $\begin{array}{l}\text { haitte } \\
\text { contain }\end{array}$ \\
\hline & & $\begin{array}{ll}\text { nai } & \text { ja } \\
\text { Neg } & \text { T }\end{array}$ & & & & & \\
\hline
\end{tabular}

"Because there is no opinion of his own."

N: Naruhodo nee. Demo maa sore wa kuizu no mondai I-see FP but well that Top quiz Gen question

$\begin{array}{llll}\text { ni } & \text { mo } & \text { yoru } & \text { yo. } \\ \text { on } & \text { also } & \text { depend } & \text { FP }\end{array}$

"I see. But well it also depends on the kinds of questions in the quiz."

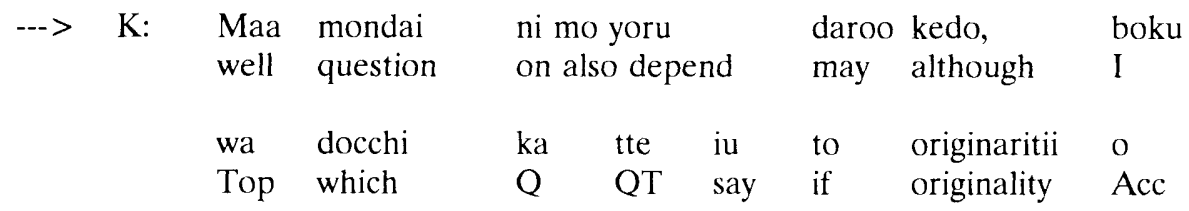

$\begin{array}{llll}\begin{array}{l}\text { motomeru } \\ \text { desire }\end{array} & \text { hoo dape } & \text { Cop } & \text { because }\end{array}$

"Well, even though it may depend on the question, (I still disagree) because I'm the kind of person who prefers originality."

At the first arrow, K directly states his disagreement with N's assessment of her friend's story. Again there is no sign of reluctance prefacing this disagreement. Then, prompted by the N's back-channel hee (which typically marks surprise) ${ }^{10}, \mathrm{~K}$ introduces an account for his disagreement (second arrow). Notice there is an intensifier zenzen "(not)

10 While the back-channel token un signals the recipient's acknowledgement and invites the speaker's continuation of the current turn, hee shows the recipient's surprise, disagreement, or lack of understanding. Further study is required with regard to such recipient responses in Japanese. 
at all" which enhances the strength of his claim.

In the next turn, $\mathrm{N}$ first shows her acknowledgement of K's opinion and then suggests a contrasting idea. Pomerantz (1984a: 74) categorizes this kind of turn, constructed of partial agreement and partial disagreement, as "weaker" disagreement compared with to those which are exclusively disagreeing without any agreeing components. Interestingly, N's weaker disagreement invites another turn of its kind, this time by K. That is, K first repeats the last half of N's preceding turn to show partial agreement and only after that produces the final kara-clause which presents another account for K's original contrasting position. Both the first and second causal elaborations are addressed to the same main clause (at the first arrow), yet the context of K's display of disagreement is transformed and weakened by N's partial agreement/partial disagreement which intervenes. In other words, $\mathrm{K}$ first asserts his position in the use of datte, and later, after N's partial agreement, makes a shift toward alignment with the recipient in the use of kara. Thus, in the choice of the causal connector, we observed the use of datte for stronger disagreement and kara for weaker.

Another aspect in the use of causal elaboration we discussed in 2.2. is the extension of a turn pursuing a recipient's preferred response. Kara and datte in Japanese are also used for this purpose, but again there is a difference in the kind of interactional problem for which each connector is used.

According to Pomerantz (1984b: 152-153), there are three types of problems which prompt speaker pursuit:

1. A recipient may not understand because a reference is unclear or a term unknown.

2. A recipient may be confused because a speaker, in referring to a matter, presumes that the recipient knows about it when he or she does not.

3. A recipient may be hesitant to respond coherently because he or she does not support, or agree with the speaker's assertion.

Of the two connectors, kara seems to be associated with the first two problems whereas datte is associated with the third. Example (16) is a case of the second problem, where there is an information gap between the speaker and the recipient. Here $\mathrm{N}$ and $\mathrm{K}$ are talking about a job application which requires a description of course work.

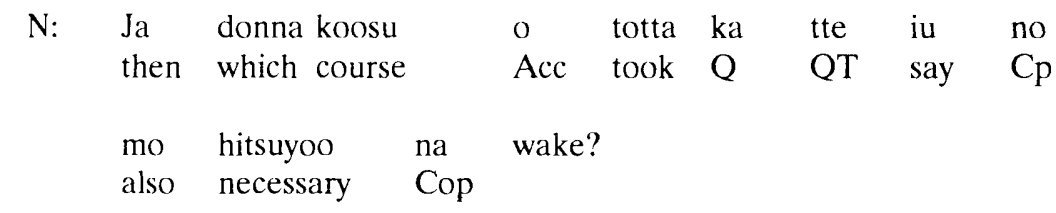

"You mean you need to write what kind of courses you've taken?" 
K: Soo. [De

right and

"Right. And"

$\mathrm{N}: \quad[$ Koko de?

here at

"Here?"

-.> K: De koko dake da to saa, boku sukunai desho? and here only Cop if FP I few Tag "And if it's only here, I don't have many, right?"

\begin{tabular}{|c|c|c|c|c|}
\hline $\mathrm{K}:$ & $\begin{array}{l}\text { Toriaezu } \\
\text { for-the-time-being }\end{array}$ & $\begin{array}{l}\text { nijuu-yon } \\
\text { twenty-four }\end{array}$ & $\begin{array}{l}\text { kurejitto } \\
\text { credits }\end{array}$ & $\begin{array}{l}\text { girigiri } \\
\text { minimum }\end{array}$ \\
\hline & $\begin{array}{l}\text { sotsugyoo suru } \\
\text { graduate }\end{array}$ & $\frac{\text { kara. }}{\text { because }}$ & & \\
\hline
\end{tabular}

"Because for the time being I'm going to graduate with the minimum twenty-four credits."

$\mathrm{N}: \quad$ Un.

un-huh

"Un huh."

In K's turn at the first arrow, he seems to presume that $\mathrm{N}$ knows the condition of his (K's) course work, and he invites acknowledgement from $\mathrm{N}$ (desho?). But the lack of response alerts $\mathrm{K}$ to a potential problem of understanding. Thus, the pause prompts an elaboration which takes the form of a kara-clause.

On the other hand, the problem in example (17), below, is not merely an informational gap but a potential disagreement. This time $\mathrm{K}$ is explaining his attitude against "rote memorization" which is a trend in Japanese education.

What we focus on in this example is the use of datte toward the end of K's turn which seems to be related to the kind of back-channels the recipient provides. Although $\mathrm{K}$ frequently uses kara in this turn, most of these clauses are placed before the main clause and are, therefore, not in question at the moment.

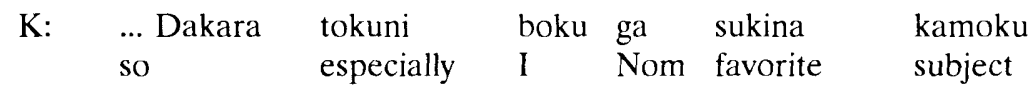




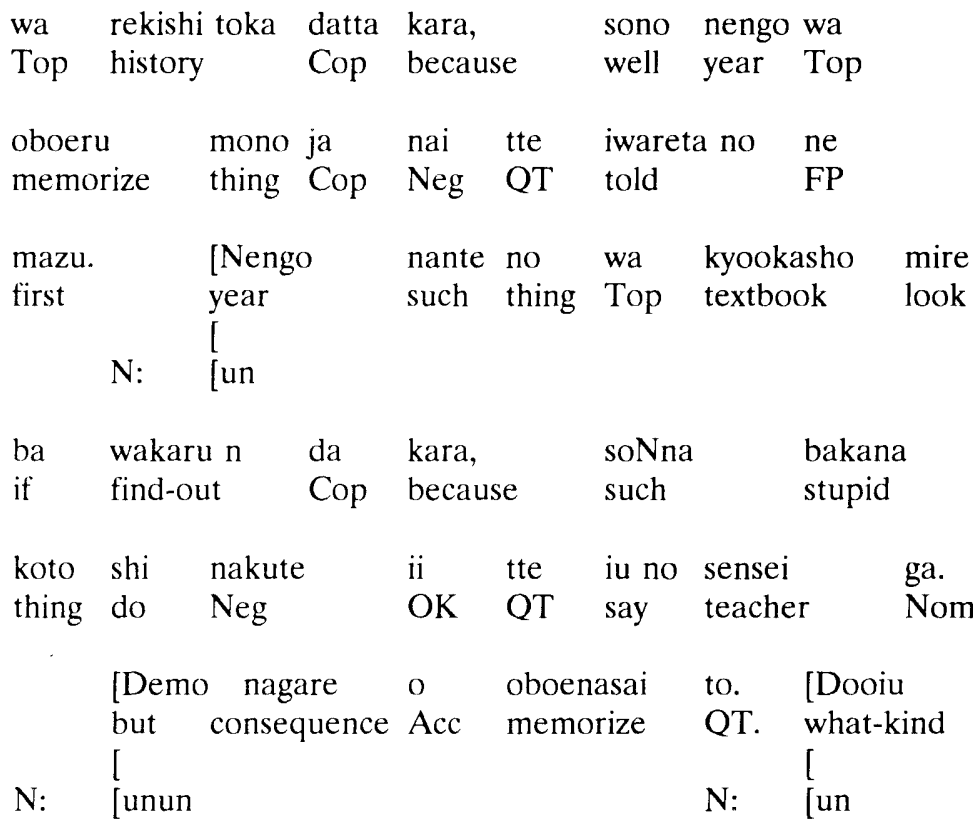

geNin de doo natta no ka toka, [socchi no hoo<smiles></smiles>

ga motto taisetsuna $\mathrm{n}$ da kara ${ }^{11}$ tte, sore de zutto Nom more important Cop because QT that with all-the-way naratte kichatta wake. [Mochiron shakaika ga learn came of-course social-studies Nom $\mathrm{N}: \quad[\mathrm{aa}$

$\begin{array}{lllll}\text { sukidatta } & \text { kara, } & \text { itsumo } & \text { benkyoo } & \text { shakaika } \\ \text { liked } & \text { because } & \text { always } & \text { study } & \text { soc.-st. }\end{array}$

ga ichiban nan te iu no juuyooshi-shiteta kara, Nom most what QT say Q emphasized because 


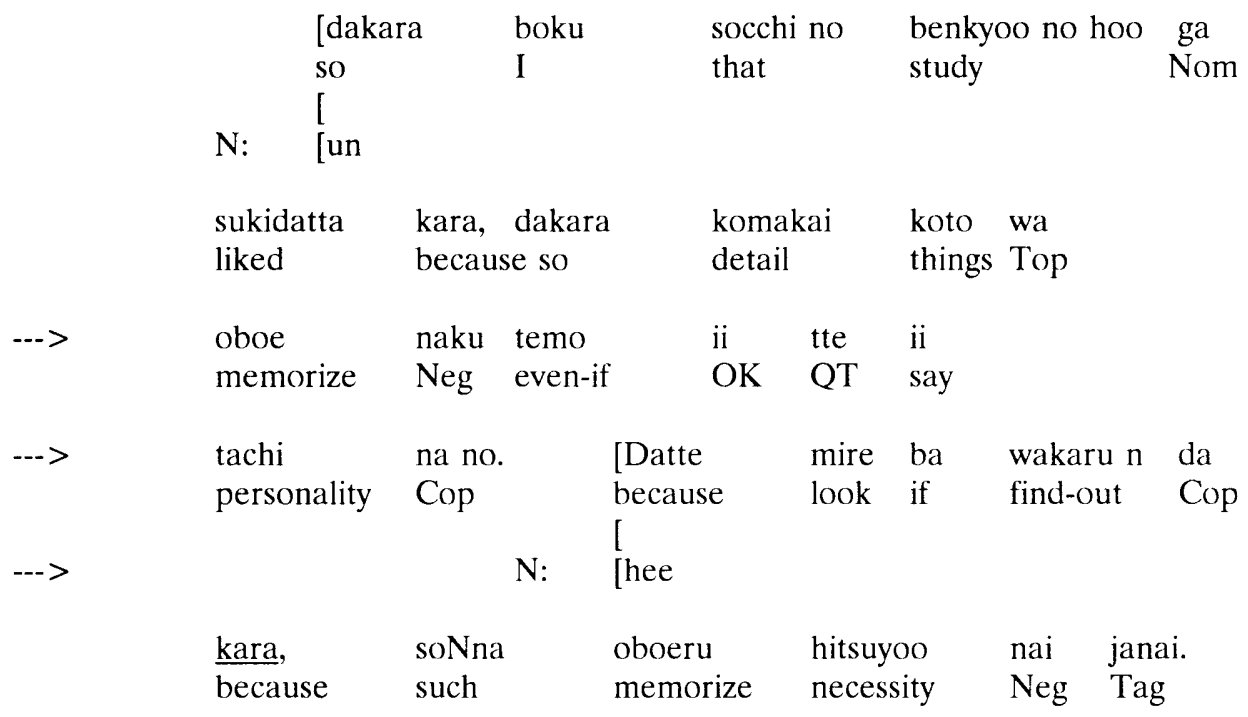

"So especially my favorite subject was like history, so first we were told that the years are not the things to memorize. (N: un) My teacher says that we can find out things like the years if we look at the textbook, so we don't have to do such stupid things. (N: unun) But he says we should memorize the consequences. (N: un) Stuff like what caused what happened, (N: un) because that's more important. I've learned things with that kind of attitude all the way through. (N: aa) Of course because I liked social studies, because I have always put emphasis on social studies, (N: un) I mean, because I liked that kind of study better, $->\quad$ that's why I tend to think that we don't have to memorize details.

$--\quad$ (N: hee) Because we can find out if we look them up, so there is no need to remember."

$\mathrm{K}$ starts his turn by providing information on his educational background which might be a little different from typical Japanese teachers' attitudes. Toward the end of K's extended turn, at the first arrow, he asserts that his attitude against rote memorization is a consequence of his past experiences and preferences. Notice that immediately after this assertion, there is a significant change in N's back-channel (as in example (15) above). While $\mathrm{K}$ was describing what his teacher said to the students, his explanation was supported by N's constant back-channeling with un, unun, or $a a$, all of which show N's acknowledgement and encourage continuation of the turn. But after the assertion of his opinion, N's back-channel changes to hee, which signals N's surprise or a possible upcoming disagreement. $\mathrm{K}$ then extends his turn with datte which provides support for his position. What is introduced by datte in this case is not information needed but a 
justification, the content of which has already been asserted previously (as reported speech, attributed to K's former teacher). Thus, there is a difference between (16) and (17): the former represents a problem in shared information while the latter represents a problem in agreement with the interlocutor's assertion.

The choice between kara and datte, then, involves the stance a speaker takes as he or she adds further support. When a speaker notices an upcoming disagreement, he or she in fact has a choice of solutions for this problem. That is, the speaker may review and evaluate his or her assertion and, if evaluated as wrong, appropriately modify the previous turn unit with an added increment (Pomerantz 1984b: 153). With the use of datte, however, the speaker does not modify his or her assertion but provides further justification for it. This means that the speaker, at that moment, is displaying more concern for making a particular point or saving his or her own face, than for maintaining the solidarity among interlocutors that might be better served by a more mitigated dispreferred turn shape (delay, partial agreement, and account with kara).

Interestingly, Maynard $(1992,1993)$ has also discussed datte and the presentation of disagreement. Maynard was not, however, examining datte relative to other connectors that function in the context of dispreferred responses. Thus, as mentioned above, her interpretation diverges from ours. Maynard sees datte as "a device to warn the listener that the upcoming turn contains self-justifying information in the context of opposition" and that the "use of datte helps encourage rapport between participants (1992: 80)." As for the English counterpart, she says that English does not have this warning device and that use of because is not a device to warn the listener but rather one which emphasizes the speaker's opposition (1993: 198).

In contrast, our comparison of turn shapes and interactional contexts in the use of datte and final kara-clauses leads to another, quite different analysis. It is difficult for us to interpret datte as "warning the listener" or "encouraging rapport". If datte were functioning as a warning to the previous speaker that the recipient was about to deliver a dispreferred response, we would expect delay and hesitation to accompany the connector. This would allow the previous speaker a chance to form a preemptive addition and possibly avoid disagreement. But in our corpus, datte is never delayed nor is it associated with hesitations. On the contrary, it is delivered without pause or hesitation. If datte were used to encourage rapport or affiliation, the recipient would offer more opportunity for avoiding delivery of the disagreement and would certainly not deliver it in the unmitigated manner which is characteristic of turns with datte in our database.

If we look in detail at the shape of the dispreferred turns where either kara or datte is used in our database, the final kara-clauses present weaker disagreements than do dattes. Kara-additions follow pauses, are associated with hesitation and prefacing, and contain disagreement components that are indirect.

A close analysis of our data suggests that kara-clauses tend to be used when a speaker is reporting experiences or events, while dattes tend to be used when the speaker is asserting his or her personal opinion, or when there is a shift from agreement to disagreement on the part of the recipient (as in the case of the backchannel shift in example (17)). These observable features in interaction lead us to 
posit a continuum of disagreement, with the two connectors tending toward its different ends. The following chart summarizes the tendencies we observe in the use of kara and datte.

FIGURE 1:

Continuum of disagreement

\begin{tabular}{|c|c|c|}
\hline & \multicolumn{2}{|c|}{ KARA <- } \\
\hline Degree of disagreement: & weaker & stronger \\
\hline Environment: & $\begin{array}{l}\text { providing "objective" } \\
\text { information }\end{array}$ & $\begin{array}{l}\text { asserting personal } \\
\text { opinion, assessment }\end{array}$ \\
\hline Problem: & information gap & difference in opinion \\
\hline Turn format: & $\begin{array}{l}\text { delay, hesitation, } \\
\text { mitigation }\end{array}$ & $\begin{array}{l}\text { no delay, hesitation, } \\
\text { nor mitigation }\end{array}$ \\
\hline
\end{tabular}

We have seen in this section that two causal connectors in Japanese are associated with similar interactional environments as is the English because. In the case of kara, $80 \%(40 / 50)$ emerge from speaker-recipient negotiation, and in the case of datte, $83 \%(34 / 41)$ arise from such interaction ${ }^{12}$.

\section{Japanese and English causal connectors}

In this section, we summarize our findings with a comparison of Japanese and English, discussing associations between distinct grammatical structures and their strategic potentials in interaction. Despite the fact that Japanese and English are typologically divergent, we find a distributional similarity involving the frequent use of the causal clauses placed after their associated main clauses. The fact that Japanese shares this tendency is especially significant as the canonical order for causal adverbial clauses in that language is before main clauses. A further similarity between Japanese and English is found in the tendency for finally placed causal clauses to appear under separate intonation contours.

In addition to showing like tendencies with respect to clause placement and intonation patterns, causal connectors in Japanese and English share functional characteristics. In both languages, causal connectors are used in the service of

\footnotetext{
12 Among the kara extensions, 16 were accounts and 12 were pursuits. Datte was used for accounts 10 times and for pursuits 12 . As with because (footnote 3 ) we include as interactionally emergent cases of collaborative construction ( 12 for kara and 12 for date).
} 
negotiating agreement (or managing disagreement) between interlocutors. In some cases, causal connectors present accounts for disagreement; in other cases, they are prompted by cues of emerging disagreement and are used to extend previously completed turns to avoid upcoming dispreferred responses. We believe that the convergent distributional and functional patterns we have found with regard to causal clauses in Japanese and English support the claim that some conversational structures and strategies, as well as their characteristic linguistic realizations, may well be universal. Aspects of the structure of social interaction seem to influence sentence construction beyond what we have come to expect based on the empirical methods commonly employed in linguistic analysis, i.e., invented examples and grammaticality judgements.

Along with the similarities summarized above, we have also observed notable differences. While English speakers exclusively use because as a causal connector in these sequences, Japanese speakers have a choice of two connectors in similar environments. On a continuum of disagreement, the connective particle kara tends to be used with information gaps and weaker disagreements, whereas datte introduces disagreements in personal opinion and has stronger contrastive force. It is interesting to ask why Japanese has these options for distinguishing level of disagreement and whether English offers any alternative ways of making like distinctions. Cultural and social differences surely play a part in accounting for the differences between English and Japanese where the potentially delicate conversational act of expressing disagreement is concerned. However, we think it is also crucial to consider the basic structural properties of the two languages as fruitful sources of explanation. Let us, therefore, discuss the dynamics of structural options and restrictions as well as interactional needs.

Of the two Japanese connectors considered here, kara is most distinct from the English conjunction because in its placement. Kara is placed at the end of a causal clause. This means that whether a kara-clause precedes or follows its main clause, the connector always occupies a position different from English because.

FIGURE 2:

Placement of kara vs. because

$\frac{\text { (main clause) }}{\text { (main clause) }} \cdot \frac{\text { kara. }}{\text { Because }}$

The existence of this exclusively clause-final connector in Japanese offers both advantages and disadvantages for achievirig interactional ends. A disadvantage is that it is not until the end of the adverbial clause that the speaker can mark the cohesive tie or the logical connection to the main clause. In the context of an initial speaker finding the need to extend a possibly complete turn, later placement of the logical 
connector means that the speaker cannot display his or her stance right at the moment when the interactional problem arises, that is, just after a delay or preface by the recipient. But this same late placement of the connector also offers an advantage if the speaker wants to mitigate the force of his or her disagreement. Thus, the delayed placement of kara in its clause makes it ideal for the presentation of weak or downgraded disagreement. This analysis also sheds light on another pattern found in our Japanese data.

Final placement of a logical connector can facilitate collaboration between speaker and recipient. Several cases in our data involve final kara-clauses which are reinterpreted by next speakers. What starts out as a final causal clause delivered by one speaker is built upon by the next speaker and thus transformed into an initial modification of a collaborative extension. The following example contains just such collaboration between a speaker and recipient.

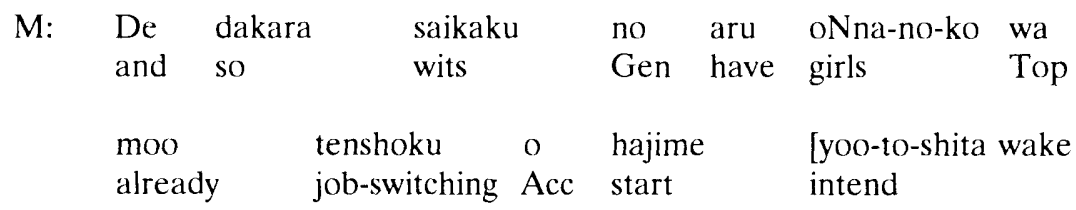

"And so some shrewd girls have started to change their job."

$$
\begin{array}{ll} 
& {[} \\
\text { E: } & {[\mathrm{U}:: \mathrm{n} .} \\
& \text { "Huun } \\
& \text { "Huun." }
\end{array}
$$
E: Aru no? Kekkoo tenshoku tte? exist Q very-well job-switching QT "Are there many jobs available?"

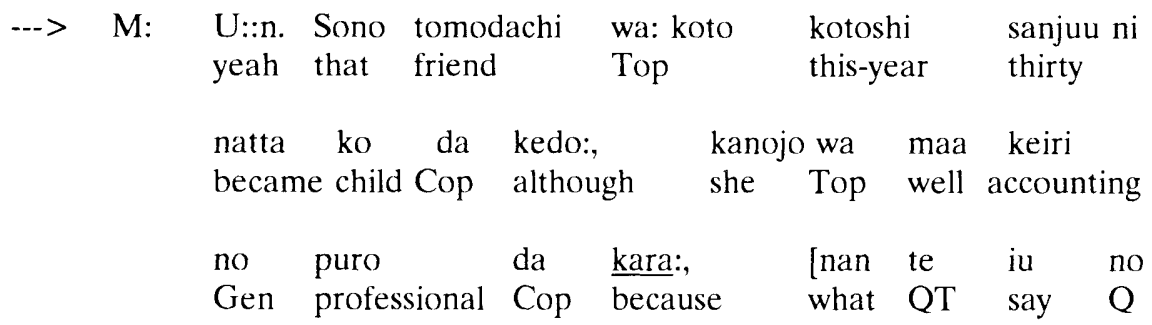

"Yea:h, that friend, she became thirty this year, but well because she is a professional accountant, so what can I say"

$$
\text { Y: [Aa: }
$$




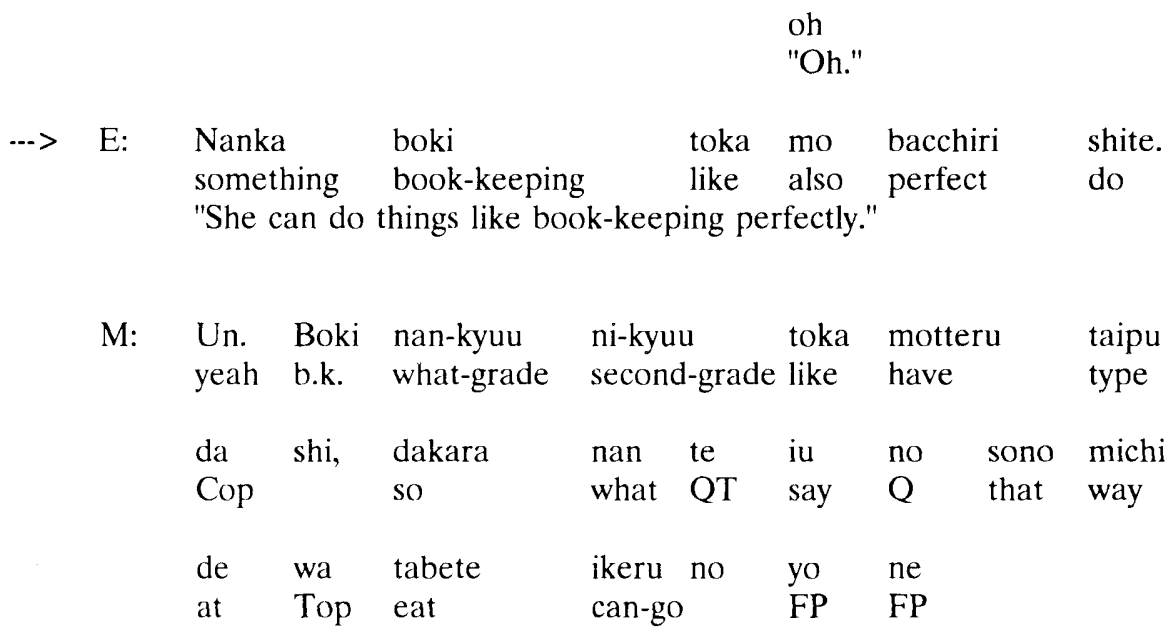

"Yeah. she is a kind of person who has things like certification for bookkeeping ability, what rate, second rate, so what can I say, she can earn some bread in that area."

M's turn at the first arrow was prompted by the E's previous question. Her answer, $u:: n$ (yea::h) with the lengthened vowel indicates her hesitation to clearly say "yes". She elaborates on her hesitation by giving information on her friend who might be an exception because of her ability. This final kara-clause is turned into an initial causal clause by E, who adds a main clause showing her understanding.

Thus, a final kara clause not only postpones the display of stance but can also create a sense of incompletion. The canonical clause order can then be exploited as a recipient adds another main clause, thereby doing further interactional work with the same kara-clause ${ }^{13}$.

In contrast with the clause-final connector kara, datte, like because, comes at the beginning of a causal clause. This offers the advantage of displaying the speaker's attitude just at the point of disagreement. This immediacy helps the speaker display stronger disagreement than is displayed with the use of clause-final kara. In addition to the benefit of early placement, datte also carries an adversative meaning, whereas kara, in itself, does not. Recall that there are cases where datte is more likely to be translated as but. In these cases, datte is still associated with justification of the speaker's position, but this justification is now introduced with the expectation of contrast with some prior claim. In fact, Japanese has the connector demo which has a

\footnotetext{
13 This collaborative use of causal extensions merits more detailed examination as well as a thorough comparison with the findings of Lerner $(1987,1991)$. The collaborative use of datte in Japanese conversation is discussed in Mori (to appear). We intend to follow this line of study as our work cont inues.
} 
simple adversative meaning, whereas datte is probably best interpreted as having both causal and adversative meaning (no because). Thus datte by itself indicates disagreement, and its placement, immediately after the element to be disagreed with, works in tandem with its inherent adversative meaning. ${ }^{14}$ As discussed in the previous section, the work of datte in disagreeing turns is also explored by Maynard (1992). She describes a function of datte appearing in clause- and/or turn-initial position as "declaring the speech act of justifying one's position in an environment of actual or suggested challenge (p.80)." However, she sees it as working to mitigate disagreement and, as we have noted, this is not in line with observations we have made about the shapes of turns associated with datte (see section 3.2, above).

Now let us consider the structural as well as functional properties of because in relation to the previous discussion of datte and kara. The placement of because is different from kara in two distinct ways. Relative to their main clauses, in our database, because-clauses are always placed finally. Whereas, in our Japanese data, kara is placed both initially (53\%) and finally (47\%). ${ }^{15}$ In addition to the difference in placement relative to main clauses, because is also distinct from kara in its position in the clausal clause proper. While because comes at the beginning of a causal clause, kara marks its completion. Both these differences in placement patterns have consequences for the interactional functions of because as compared with those of kara.

Japanese speakers are flexible in their interpretation of kara-clauses as either initial or final. Thus, what is, in the first place, delivered as a final kara-clause can be transformed into an initial subordinate clause through a recipient's collaborative extension. The final placement of kara within the causal clause itself also makes such a cause amenable to reinterpretation. Thus, it can be reinterpreted by a recipient as a medial rather than final connector in a clause complex., i.e. it can be changed into a connector between a causal clause and its main clause (now delivered by the next speaker). In contrast to the flexibility shown in the use of kara, because-clauses, in our data, are exclusively postposed, and never reinterpreted as initial by next speakers. By appearing at the beginning of causal clauses, which tend to be quite long relative to other adverbial clauses (Ford 1993), because is less available for reuse than is the clause-final kara. Our analysis, thus, shows striking differences between because and $k a r a$, both in structural distribution, frequency patterns of clause placement, and in interactional functions associated with these patterns of structure and use.

Because is also distinct from the Japanese causal connector datte. While because and datte occupy the same location in a clause, they have different semantic and interactional interpretations. The English conjunction does not carry the strong implication of disagreement associated with its Japanese counterpart. Unlike datte, which can be translated as but or possibly no because, English because does not in itself

\footnotetext{
14 Morita (1980) discusses the difference between datte and demo.

15 As discussed in section 3.1, the frequency of final placement of kara clauses in Japanese is still quite high relative to temporal and conditional clauses, which are used finally only $9 \%$ of the
} time in the same database. 
express contrast or disagreement. ${ }^{16}$ It is assumed, however, that there also exists a continuum of disagreement in English conversation. Pomerantz (1984a) explicitly mentions strong and weak shapes of dispreferred responses, though that difference is not the primary focus of her study. To our knowledge, the management of the strength of disagreement in English is done not by the choice of connector but with other devices such as timing of turn onset, stress, use of intensifiers, choice of evaluative language, directness of the disagreeing component, and, of course, non-verbal expressions. The following is an example of because in what we believe is a possible environment for the use of datte in the expression of stronger disagreement.

(19) Because accounting for a dispreferred response. Discussion of V's father's knee operation. (V116)

V: So it's straight- it's- [it's- it's out like that now.
C:
[That's ama:zing.
C: Is that what your mom thought was unnecessary
$->\quad$ V:
[now?
thinks that the whole thing's unnecessary. Cause he- he's in so much
pain, that it seems like he's never going to walk again.

In example (19), V's disagreement is not delayed but is, in fact, overlapping with C's question. Furthermore, the no is delivered directly, without mitigation, and is accompanied by intensification (whole, so, never) as well as emphatic stress (on thing's, so, and walk). Thus, while English does not seem to offer a connector with the equivalent adversative force of Japanese datte, English conversationalists can make use of timing, directness, intensifiers, and stress to achieve a similar type of strong disagreement ${ }^{17} 18$.

In sum, Japanese has two different causal connectors which offer speakers options for displaying disagreement. The connective datte communicates a different speaker attitude, i.e., stronger disagreement, in addition to the logical connection which is expressed with kara alone ${ }^{19}$. On the other hand, English grammar, which has only

\footnotetext{
16 raking the issue of early or later placement a logical step further, we speculate that due to its initial placement, because may be associated with stronger disagreement than the final Japanese connector kara.

17 Interestingly, Susanne Günthner (1993) has found similar non-delayed, unmitigated disagreement patterns used by German speakers in argumentative interchanges. "Dissent format" is the label she offers for a pattern whereby disagreeing turns are delivered in preferred turn shapes.

18 It is not clear to us how the distinction between personal opinion and information gaps is captured in responses to pauses and pre-dispreferred markers in English conversations (see discussion of datte and kara above).

19 Maynard (1992) claims that the meaning of discourse connectives falls outside the scope of referential semantics, based on the analysis of Japanese connectives. She uses the term "Discourse Modality" in a broad sense to characterize this expanse of meaning.
} 
one slot for the causal connector, does not offer the structural advantage associated with kara, which not only delays the presentation of logical connection but also invites collaboration and negotiation towards alignment ${ }^{20}$. We have also suggested that because does not have the inherent contrastive meaning that is associated with datte.

\section{Conclusion}

Our findings regarding the use of causal connectors in managing disagreement in both Japanese and English support the hypothesis that there are needs and constraints in human interaction that affect the shape of turns and the use of grammar in typologically distinct languages. ${ }^{21}$ In addition, our data suggest that cross-linguistic differences in the options for clause combining allow for different realizations of turn shapes. The Japanese clause-final causal connector kara seems well-suited for presenting mitigated dispreferred turns and for inviting collaboration, while the clauseinitial causal connector datte is better suited for presenting strong disagreement. English, with the exclusive option of clause initial causal connection, offers other devices for mitigating and intensifying the strength of disagreement. While "universal" forces in human interaction clearly influence the use of grammar, typological differences also create advantages and disadvantages in the achievement of certain interactional functions. We look forward to examining both structural and cultural differences in more detail in future research, with a particular focus on the role of nonverbal communication and varieties of backchannel responses in the prompting of one or another choice of turn format or grammatical connector.

Appendix: Symbols used in Japanese examples

$\begin{array}{ll}\text { Acc } & \text { accusative case } \\ \text { Cop } & \text { copula } \\ \text { Cp } & \text { complementizer } \\ \text { Gen } & \text { genetive case } \\ \text { FP } & \text { sentence-final particle } \\ \text { Neg } & \text { negative morpheme } \\ \text { Nom } & \text { nominative case } \\ \text { Tag } & \text { tag-like expression } \\ \text { Top } & \text { topic marker } \\ \text { Q } & \text { question marker } \\ \text { QT } & \text { quotative marker }\end{array}$

20 In English, so or though may be placed clause-finally in conversation. The placement of these connectors in turn-final position calls for attention in future studies.

21 Research by fox et al. (1993) supports this same hypothesis. 


\section{References}

Brown, Penelope and Stephen C. Levinson (1978) Politeness: Some universals in language usage. Cambridge: Cambridge University Press.

Chafe, Wallace C. (1984) How people use adverbial clauses. Proceedings of the Tenth Annual Meeting of the Berkeley Linguistics Society.

Danielewicz, Jane and Wallace L. Chafe (1985) How 'normal' speaking leads to 'erroneous' punctuating. In Sarah Warshauer Freedman (ed.), The acquisition of written language. Norwood, NJ: Ablex, pp. 213-25.

Davidson, Judy (1984) Subsequent versions of invitations, offers, requests, and proposals dealing with potential or actual rejection. In J. Maxwell Atkinson and John Heritage (eds.), Structures of social action. Cambridge: Cambridge University Press.

Duranti, Alessandro (1988) Ethnography of speaking: toward a linguistics of the praxis. In Frederick A. Newmeyer (ed.), Linguistics: The Cambridge survey - Volume IV Language: The socio-cultural context. Cambridge: Cambridge University Press, 210-228.

Duranti, Alessandro ad Elinor Ochs (1979) Left-dislocation in Italian conversation. In Talmy Givón, (ed.), Discourse and syntax. New York: Academic Press, 377-416.

Ford, Cecilia E. (1992) Variation in the intonation and punctuation ofdifferent adverbial clause types in spoken and written English. In Pamela Downing, Susan D. Lima, and Michael Noonan (eds.), The linguistics of literacy. Amsterdam: Benjamins, 3-16.

Ford, Cecilia E. (1993) Grammar in interaction: Adverbial clauses in American English conversations. Cambridge: Cambridge University Press.

Ford, Cecilia A., and Sandra A. Thompson (1986) Conditionals in discourse: A text-based study from English. In E. Traugott, C. Ferguson, J. Snitzer Reilly, and A. ter Meulen (eds.), On conditionals. Cambridge: Cambridge University Press.

Ford, Cecilia A., and Sandra A. Thompson (In press) Interactional units in conversation: syntactic, intonational, and pragmatic resources for the management of turns. In Elinor Ochs, Emanuel A. Schegloff, and Sandra A. Thompson (eds.), Interaction and grammar. Cambridge: Cambridge University Press.

Fox, Barbara A. (1987) Discourse structure and anaphora: Written and conversational English. Cambridge: Cambridge University Press.

Fox, Barbara, Makoto Hayashi and Robert Jasperson (Manuscript). Resources and repair: a crosslinguistic study of the syntactic organization of repair. Department of Linguistics, University of Colorado, Boulder.

Fujii, Yoko (1992) The order and functions of adverbial clauses in Japanese spoken discourse. In Mejiro Linguistic Society, 109-123.

Goffman, Erving (1955) On face-work: An analysis of ritual elements in social interaction. Psychiatry 18: 213-31. 
Goodwin, Charles (1979) The interactive construction of a sentence in natural conversation. In George Psathas (ed.), Everyday language: Studies in ethnomethodology. New York: Irvington, 97-121.

Goodwin, Charles (1981) Conversational organization. Interaction between speakers and hearers. New York: Academic Press.

Goodwin, Charles, and John Heritage (1990) Conversation analysis. Annual Review of Anthropology 19: 283-307.

Gumperz, John J. (1982) Discourse strategies. Cambridge: CambridgeUniversity Press.

Günthner, Susanne (1993) "No. That's not right. I see it totally different"- Differences in contextualization conventions in German-Chinese argumentations. Paper presented at the 4 th International Pragmatics Conference. July 25-30, 1993, Kobe, Japan.

Heritage, John (1984) Garfinkel and ethnomethodology. Cambridge: Polity Press.

Kim, Kyu-hyun and Kyung-Hee Suh (To appear) An interactional account of nikka in Korean converstion. Santa Barbara Working Papers in Linguistics.

Lerner, Gene H. (1987) Collaborative turn sequences: sentence construction and social action. Unpublished Ph.D. dissertation. University of California, Irvine.

Lerner, Gene H. (1991) On the syntax of sentences-in-progress. Language in Society 20: 441-458.

Levinson, Stephen C. (1983) Pragmatics. Cambridge: Cambridge University Press.

Linde, Charlotte, and William Labov (1975) Spatial networks as a site for the study of language and thought. Language 51: 924-39.

Matsumoto, Yo (1988) From bound grammatical markers to free discourse markers: history of some Japanese connectives. Proceedings of the 7th Annual Meeting of the Berkeley Linguistics Society, 340-351.

Maynard, Senko (1992) Speech act declaration in conversation: Functions of the Japanese connective datte. Studies in Language 16(1): 63-89.

Maynard, Senko (1993) Kaiwa no hyoogen no taishoo: setsuzoku no hyoogen o megutte. [Contrastive analysis of conversational expressions: on the expression of conjunctions.] In Kaiwa Bunseki (ed.), [Conversation Analysis]. Tokyo: Kuroshio Shuppan.

Mori, Junko (To appear) Functions of the connective datte in Japanese conversation. In Japanese/Korean Lingusitics, Vol. 4. CSLI, Stanford University.

Ochs, Elinor, Emanuel A. Schegloff, and Sandra A. Thompson (eds) (In press) Interaction and Grammar. Cambridge: Cambridge University Press.

Ono, Tsuyoshi, and Ryoko Suzuki (1992) Word order variability in Japanese conversation: Motivation and grammaticization. Text 12: 429-445. 
Ono, Tsuyoshi, and Sandra A. Thompson (Manuscript) What can conversation tell us about syntax? Department of Linguistics, University of California, Santa Barbara.

Pomerantz, Anita M. (1978) Compliment responses: Notes on the co-operation of multiple constraints. In J. Schenkein (ed.), Studies in the organization of conversational interaction. New York: Academic Press, $79-112$.

Pomerantz, Anita M. (1984a) Agreeing and disagreeing with assessments. In J. Maxwell Atkinson, and John C. Heritage, (eds.), Structures of Social Action. Cambridge: Cambridge University Press, 57-101.

Pomerantz, Anita M. (1984b) Pursuing a response. In J. Maxwell Atkinson, and John C. Heritage, (eds.), Structures of social action. Cambridge: Cambridge University Press, 152-163.

Ramsay, Violeta (1987). The functional distribution of preposed and postposed "if" and "when" clauses in written narrative. In R.S. Tomlin (ed.), Coherence and grounding in discourse. Amsterdam: Benjamins.

Sacks, Harvey (1987) On the preference for agreement and contiguity in sequences in conversation. In Graham Button, and John R.E. Lee (eds.), Talk and social organisation. Philadelphia: Multilingual Matters.

Sacks, Harvey, Emanuel A. Schegloff, and Gail Jefferson (1974) A simplest systematics for the organization of turn-taking for conversation. Language 50(4): 696-735.

Schegloff, Emanuel A. (1972) Sequencing in conversational openings. In J.J. Gumperz and D.H. Hymes (eds.), Directions in sociolinguistics. New York: Holt, Rinehart \& Winston, 346-380.

Schegloff, Emanuel A. 1(982) Discourse as an interactional achievement: some uses of 'uh huh' and other things that come between sentences. In Deborah Tannen (ed.), Analyzing discourse: Text and talk. Georgetown: Georgetown University Press, 71-93.

Schegloff, Emanuel A., Gail Jefferson, and Harvey Sacks (1977) The preference for self-correction in the organization of repair in conversation. Language 53: 361-82.

Schegloff, Emanuel A., and Harvey Sacks (1973) Opening up closings. Semiotica 7(4): 289-327.

Schiffrin, Deborah (1985) Multiple constraints on discourse options: A quantitative analysis of causal sequences. Discourse Processes 8: 281-303.

Schiffrin, Deborah (1988) Conversation analysis. In Frederick Newmeyer (ed.), The Cambridge Survey. Cambridge: Cambridge University Press, 251-276.

Simon, M. E. (1989) An analysis of the postposing construction in Japanese. Unpublished Ph.D. dissertation. University of Michigan.

Taylor, Talbot J., and Deborah Cameron (1987) Analysing conversation. Oxford: Pergamon Press. 